\title{
Arte Precolombino Andino
}

María José Herrera *

\section{Resumen / Arte Precolombino Andino}

El objetivo de este trabajo es presentar una serie de ideas que inspiraron la concreción del guión curatorial y museográfico de la sala de Arte Precolombino Andino del Museo Nacional de Bellas Artes, un trabajo interdisciplinario en el que participaron historiadores del arte, etnógrafos, museólogos y diseñadores. Del guión científico al curatorial y de éste al montaje efectivo, se desenvuelven distintas instancias tales como la adecuación del diseño a las necesidades comunicativas y su adaptación a los códigos altamente formalizados de la sala de un museo.

\section{Palabras clave}

Arte Precolombino - Diseño - identidad - museo.

\section{Summary / Andean Pre-Columbian Art}

The objective of this work is to present a series of ideas that inspired the concretion of the curatorial and museum script of the room of Andean Pre-Columbian Art of the National Museum of Arts, an interdisciplinary work in which participated historians of the art, etnógrafos, museólogos and designers. From the scientific script to the curatorial and of this one to the effective assembly, different instances develop such as the adjustment of design to the communicational needs and its adaptation from the codes highly formalized of the room of a museum.

\section{Key words}

Design - identity - museum - Pre Columbian Art.

\section{Resumo / Arte Precolombino Andino}

O objetivo deste trabalho é apresentar uma série de idéias que inspiraram a concretização do roteiro curatorial e museográfico da sala de Arte Precolombino Andino do Museu Nacional de Belas Artes, um trabalho interdisciplinario no que participaram historiadores da arte, etnógrafos, museólogos e desenhistas. Do roteiro científico ao curatorial e deste ao montagem efetiva, desembrulham-se diferentes instâncias tais como a adequação do desenho as necessidades comunicativas e sua adaptação aos códigos altamente formalizados da sala de um museu

\section{Palavras clave}

Arte Precolombino - design - identidade - museu.

* Licenciada en Historia del Arte (Universidad de Buenos Aires). Jefa del Departamento de Investigación y Curadoría del Museo Nacional de Bellas Artes, Buenos Aires, República Argentina. 
Los museos establecen modelos ejemplares para leer los objetos como evidencias, representaciones, reflexiones (...) hacen legible a lo visible. Determinan qué es lo que vale o no la pena ser visto, enseñando a sus visitantes el modo de leer lo visible, enseñándoles a activar la memoria social. (Preziosi, D., 1998: p.509)

En noviembre del 2005 se inauguró la sala permanente de arte precolombino del Museo Nacional de Bellas Artes (MNBA). ${ }^{(1)}$ La sala completó el guión curatorial del museo que, desde enero del 2004, reorganizó sus espacios de exhibición de arte europeo y argentino. Arte Precolombino Andino lleva por título esta instalación que pone el énfasis en destacar los aspectos estéticos de las piezas, tal como lo hicieron en su momento pioneros como el arqueólogo Alberto Rex González y coleccionistas como Guido Di Tella, a quienes debemos la formación de este conjunto actualmente patrimonio del MNBA.

Esta sala es la primera en su género, es decir, la primera en un museo de arte. Así, legitima el valor y especificidad del arte precolombino instalándolo en el discurso que sobre la historia del arte exhibe el mayor museo de nuestro país. El MNBA puso en valor el arte indígena antiguo y lo ofrece para el estudio y discusión de los públicos actuales en el contexto de un museo de arte.

El objetivo de este artículo es contar cuáles fueron las ideas que inspiraron la concreción del guión curatorial y museográfico de la sala de Arte Precolombino Andino, un trabajo interdisciplinario entre historiadores del arte, etnógrafos, museólogos y diseñadores. Del guión científico al curatorial y de éste al montaje efectivo, se desenvuelven distintas instancias tales como la adecuación del diseño a las necesidades comunicativas y su adaptación a los códigos altamente formalizados de la sala de un museo.

Las piezas exhibidas fueron creadas por los pobladores originarios de los Andes en tiempos en que arte, religión y vida cotidiana no eran esferas separadas. La escisión de estos ámbitos, y la consecuente autonomía del arte, son conceptos históricos de Occidente que se remontan al Renacimiento europeo. El arte precolombino es producto de la creación colectiva en el seno de distintas sociedades que así expresaron su cosmovisión y las relaciones sociales que las vincularon. Como en todo arte ligado a la religión, las innovaciones estilísticas se producen a un ritmo lento. A través de los siglos comprobamos cómo determinadas soluciones plásticas se convirtieron en patrones de gran persistencia que se difundieron vastamente al punto de desdibujar los límites cronológicos y territoriales de origen Es también peculiar del arte amerindio una unidad indisoluble entre lo estético y lo funcional. La distinción entre arte puro o aplicado es inoperante en este contexto. ${ }^{(2)}$

No obstante el avance en los estudios del arte indígena precolombino, no se puede soslayar el hecho de que la mayoría de las piezas que se conocen son fruto de excavaciones no científicas o simples saqueos de sitios. Así, la ausencia del contexto original de las piezas ha hecho muy difícil la labor de los especialistas en la atribución, datación e interpretación.

El arte precolombino y, en general, el no occidental han estado sujetos a distintas valoraciones, desde la visión romántica, que apuntaba a su pureza e incontaminación, hasta las apropiaciones formales de las vanguardias europeas, con Picasso como paradigma. Desde entonces, tanto artistas como críticos e historiadores vieron en este arte -entonces llamado primitivo- su carácter de modernidad. En este espíritu de época fue formada la ex colección Di Tella. Independientemente de las condiciones históricas y sociales que dieron origen a estas producciones, una belleza basada en las formas, unía al arte precolombino con el arte moderno. Así, el coleccionista reconocía las líneas de Henry Moore en el artista anónimo de un suplicante de la cultura Alamito, mientras las formas cóncavo-convexas de la escultura de Moore que recibía al público en el hall de entrada del Instituto Di Tella, en la calle Florida, podían establecer una conexión sensible con un remoto artista de nuestro territorio. A partir de sus viajes a México, Guido Di Tella reconoció la importancia de dar a ese corpus simbólico, susceptible de distintas apropiaciones -entre ellas la estética-, un uso social que, a juicio del coleccionista, permitiría "un mayor diálogo con nuestra cultura de hoy" ${ }^{(3)}$. Por eso quiso que el destino de su colección no fuera otro que el de un museo público, el de Bellas Artes.

\section{Las estrategias curatoriales. Curaduría y museografía}

El Museo Nacional de Bellas Artes reúne alrededor de 14.000 obras entre pinturas, esculturas, grabados, fotografías, y objetos. Sus salas permanentes, ordenadas según una línea cronológica del arte occidental desde el Medioevo europeo hasta la actualidad, nunca habían tenido al arte precolombino como parte de su relato. Incorporarlo, suponía romper con ciertos códigos dentro de la propia museografía. Por tratarse de un museo de arte, nuestra aproximación debía ser desde la historia del arte y la estética. Los formatos propios de la etnografía (clasificación por culturas, taxonomías de objetos, reconstrucciones de sitios y otros) estaban fuera de nuestro horizonte. No obstante, se imponía un trabajo interdisciplinario que permitiera interpretar esos particulares objetos a exhibir. ${ }^{(4)}$

Para la etnografía las piezas precolombinas son consideradas artefactos, objetos en el límite entre lo funcional y lo artísticoartesanal. Nuestra intención era destacar este último aspecto sin por ello caer en el riesgo de la espectacularización del patrimonio o la pérdida del contexto simbólico. ${ }^{(5)}$ De modo que la selección de obras respondió a un cruce entre la importancia simbólica-etnográfica de la pieza y su valor estético.

La exposición se dividió en cuatro núcleos temáticos donde conviven piezas de distintas culturas y momentos históricos. Como señaláramos más arriba, estas piezas tienen en común ser evidencias de la religiosidad y del status político de los pueblos que las crearon. Estas interpretaciones aportadas por la arqueología, sirvieron de hilo conductor para el guión curatorial.

El diseño espacial fue encarado a partir del uso de una serie de recursos escenográficos que comunicasen un clima de espiritualidad coherente con el origen de las obras exhibidas. El minimalismo, la síntesis formal tanto en la arquitectura como en dispositivos de exhibición (vitrinas, diseños de cartelería) fue el criterio elegido para destacar de un modo silencioso el propio carácter sintético de las piezas. ${ }^{(6)}$ La ortogonalidad de la arquitectura alude a la arquitectura andina en la que predominan los muros macizos, bajos, de contundente corporeidad. Las dos áreas principales, la de las piezas precolombinas argentinas y los textiles peruanos, se interconectaron visualmente por medio de las transparencias producidas por vitrinas pasantes o el acceso bilateral. Esta decisión del diseño responde al guión curatorial que propone la existencia de un mundo simbólico común para toda el área andina, desde Colombia hasta el centro de Chile. El diseño de la iluminación apunta a crear un clima mágico donde la luz no muestra sino que revela lo oculto. Así, la luz pasó a ser un elemento fundamental de la propuesta museográfica en tanto establecía el tono general de la exposición, a la vez que permitía acentuar las cualidades estéticas de las piezas. Los distintos ángulos de la luz, la incorporación de vitrinas con fuentes 
lumínica desde abajo hacia arriba, permitió destacar texturas, enfatizar líneas, contrastar y proyectar sombras que agregaron misterio y dramatismo a la puesta en escena. También el uso de soportes neutros de acrílico transparente y la gama de grises acerados presente en las paredes, telas e interiores de vitrinas, colaboró a crear una atmósfera de misticismo en el que los objetos parecen levitar ante nuestros ojos.

El primer núcleo, El espíritu de la piedra, reúne piezas en su mayoría del período Temprano (1500 a. C. al 300 d. C) realizadas en piedra. La talla de la piedra fue una de las artes en que se manifestó el mundo religioso y mítico de las poblaciones originarias de la región de los Andes. Antes del inicio de la era cristiana, en el Noroeste del actual territorio argentino, se desarrolló esta tradición artística, intensa y breve, que expresa el culto andino dedicado a conmemorar en la piedra la memoria de los ancestros. ${ }^{(7)}$

En este núcleo se destacan las figuras que los arqueólogos denominan suplicantes ${ }^{(8)}$. Se trata de esculturas de bulto -notables por su despliegue de refinamiento artístico y la singular concepción plástica- que juegan con el audaz recurso de espacios vacíos envolventes. Fueron la representación grabada en piedra del ancestro fundador del grupo social.

Temáticamente, el núcleo introduce en el mundo del culto a los antepasados. Así, los menhires son las marcas en piedra del paisaje sagrado construido por la acción de los ancestros, quienes, a su vez, eran el fundamento de la identidad social del grupo asentado en el territorio. Morteros y vasos de piedra son un conjunto de bienes ceremoniales que muestran una inquietante belleza en las representaciones de hombres y felinos, casi sobre la frontera de lo siniestro. Fueron objetos utilizados para rituales con sustancias alucinógenas.

Por medio del análisis iconográfico identificamos formas, vinculaciones estilísticas entre distintas culturas y períodos que se reflejan en el guión curatorial. Para evidenciar estas conexiones se usaron pequeños textos (cédulas o pie de obra) que, por ejemplo, mostraban la existencia de una resolución formal en la representación de la figura humana (la unión de las dos cejas con la nariz formando una " $T$ ") desde el período Temprano hasta los momentos previos a la llegada de los españoles. Como señaláramos al comienzo, en general en el arte religioso, las soluciones formales perduran vigentes por largos períodos y hasta pueden redundar en estereotipos.

El segundo núcleo, El mundo simbólico, exhibe piezas cerámicas de distintas culturas donde se desarrolla plenamente la iconografía de la cosmovisión andina. El texto de pared incluido en este núcleo, informa sobre el mundo de las creencias en el área andina: una religión basada en los fenómenos celestes (en la cual el sol tiene un lugar de importancia), el culto a los antepasados y la sacralización de las fuerzas de la naturaleza. Los textos de pie de obra enfatizan la presencia del felino, la serpiente y la figura humana asociadas al culto solar y sus modos de representación: el sol (inti o punchao en quechua) un personaje vestido con la tradicional túnica andina (el uncu) y adornos metálicos en la frente y los brazos, escoltado por jaguares y víboras, o la deidad solar que aparece como sacrificado ( en una mano empuña un hacha y, en la otra, trae colgando una cabeza cercenada).

En este núcleo también se exhiben los enseres para el ceremonial: las pipas y morteros con que se consumía y preparaba la vilca o cebil, el poderoso alucinógeno que los chamanes o sacerdotes utilizaban para transportarse al mundo de los seres sagrados. Así, la presencia de imágenes que combinan rasgos humanos y animales, no son interpretadas como parte de la imaginación del productor de la pieza sino como evidencias de las transformaciones ocurridas a lo largo del viaje chamánico. En este punto se hizo necesario recurrir a la interpretación etnográfica ya que la artística hubiera quitado espesor a esas imágenes surgidas del contexto de un ritual religioso. Con este mismo marco fueron leídos como objetos propiciatorios, dos piezas que, desde la perspectiva de la historia del arte occidental, debieran ser de arte erótico: un mortero de piedra que representa a un onanista y una vasija bilobular formada por dos cuerpos copulando.

Los textos de pared y los de pie de obra señalan otras características del arte precolombino como la frontalidad en el más antiguo, la insistencia en las figuras desdobladas en simetría especular y la oposición naturalismo-abstracción presente en la representación en distintas culturas. Desde una verista serpiente enroscada tallada en piedra hasta los círculos concéntricos que representan sintética y simbólicamente el pelaje del dios- felino, el visitante puede observar las distintas soluciones formales a través del tiempo.

En el núcleo Imagen y Poder, el tercero, se exhiben piezas del período denominado de los Desarrollos regionales (1000- 1450 d. C), cultura Santamariana y el Incaico (1450- 1535 d. C). Este apartado pone énfasis en la metalurgia y sus usos prácticos y simbólicos. Si bien la colección tiene piezas de metal desde el período Temprano, el guión se circunscribe a exhibir las del tardío para mostrar la importancia de la metalurgia en las tecnologías de la guerra. Así, además de instrumentos de trabajo, las piezas metálicas formaron parte de la parafernalia de la guerra, bienes de alto valor simbólico ligados a la mostración del poder temporo-religioso. Las hachas ceremoniales, pectorales, diademas y otros ornamentos, denotaban la posición privilegiada de quien los poseía en las jerarquías sociales. Desde la perspectiva religiosa, los metales, por su color y capacidad de reflejar el intenso brillo del sol, se asociaban al culto solar.

En el siglo XI d. C. los avances técnicos permitieron fundir bronce con aleación de estaño. Tiempos de un contexto sociopolítico complejo que desembocó en la integración de diversidades étnicas en los distintos valles. Son típicos de este momento los discos fundidos en bronce usando moldes de cerámica, su lenguaje artístico es austero por la síntesis lineal en la representación de serpientes bicéfalas, figuras humanas, cabezastrofeo y motivos geométricos. ${ }^{(9)}$ En algunos casos -como el de la cultura Santamariana exhibido en la sala- los discos metálicos estaban parcialmente pintados de color. Este disco fue una pieza central del guión curatorial. Objeto de excepcional valor estético, expresa una concepción religiosa, política y estética, que sintetiza las etapas anteriores. Colocado sobre una pared en el eje del acceso a la sala, su presencia es visible desde todos los espacios internos del recorrido.

Por último, los Textiles andinos, de las culturas Paracas y Nazca del actual Perú, muestran el universo compartido por el área andina. Antes de la conquista europea el área occidental de Sudamérica se extendía desde el sur de Colombia hasta el centro de Chile.

En los Andes el arte textil se remonta a épocas muy antiguas, anteriores al pleno desarrollo de la agricultura. Las piezas de este núcleo hablan de la importancia del tejido no sólo como elemento básico para la vestimenta, sino que, junto con los metales, eran los bienes de más alto valor. Al igual que en las demás manifestaciones de la cultura material, en los textiles se plasmó el mundo espiritual y sus simbolismos. Como señalan los textos en la sala son "un elocuente testimonio del ceremonial, las jerarquías sociales y las complejas formas de cálculo numérico imprescindibles para su confección". 
Las delicadas telas fueron montadas sobre bastidores forrados en tela oscura para contrastar y, de esta manera evidenciar los dibujos, tejidos o bordados, de los textiles. También en algunos casos fueron iluminados desde abajo para resaltar la levedad de las telas.

La sala está ambientada con una selección de Moche el llamado de los muertos de José Pérez de Arce, musicólogo que reconstruyó el sonido de los antiguos instrumentos autóctonos. Esta música de vientos y sonidos inspirados en la naturaleza colabora a crear el clima de espiritualidad que se propone el guión.

\section{Las intenciones}

Tanto desde el guión curatorial como del diseño, la instalación de la sala de Arte Precolombino Andino en el MNBA se propuso destaca el valor artístico de este patrimonio. Cumpliendo con la finalidad educativa que es razón de ser histórica del museo moderno, la sala provee al visitante de elementos conceptuales que la arqueología ha investigado, para sumarlos a la interpretación estética y así acercar algunas de las ideas que dieron origen a este arte. Conocer y reconocer es parte del ejercicio de identidad que los museos proveen. ${ }^{(10)}$

El museo es "un foro o lugar de conversación, encuentro e intercambio, de socialización y negociación de identidades, una puerta hacia la investigación y la inspiración de nuevas ideas (...) un lugar donde se proponen lecturas, interpretaciones o visiones sin evadir la controversia (...) en su concepción más contemporánea, es un medio de comunicación colectiva y como tal, agente de la democratización de la cultura".(11)

Exhibir y contar: dos funciones que el museo ejerce sobre su patrimonio. Los museos implican un espacio de representación y generan políticas. De allí su importancia. Si como García Canclini propone entendemos al patrimonio como un capital cultural, estaremos ante la evidencia de que dicho capital estuvo, está y estará, inmerso en un proceso social de legitimación. El patrimonio no es un conjunto de bienes estables y neutros sino que está sujeto a luchas materiales y simbólicas por parte de las clases, etnias y grupos. ${ }^{(12)}$ De allí la relevancia histórica de esta primera sala permanente de arte precolombino en un museo de arte.

\section{Notas}

1 Preziosi, D. (1998). The Art of Art History: a Critical Anthology, Oxford New York: Oxford University Press, p. 509.

2 Guión curatorial: María José Herrera y María Florencia Galesio; Diseño museográfico y montaje: Valeria Keller y Mariana Rodríguez.

3 “El ornamento -señaló el artista y teórico César Paternosto-, lejos de ser un agregado para embellecer, es "una lección de abstracción de antiguos simbolismos sancionados por el grupo social." en Paternosto, C. (2001). Abstracción, el paradigma amerindio, Valencia: IVAM, p. 25.

4 Entrevista de Ana Canakis a Guido Di Tella. (1994). MNBA, Arte Precolombino de la Argentina, Buenos Aires, p. 11.

5 El asesoramiento académico fue brindado por el Dr. José Antonio Pérez Gollán (ex Director del Museo Etnográfico "Juan B. Ambrosetti" y actual director del Museo Histórico Nacional), la Lic. María Alba Bovisio (Facultad de Filosofía y Letras) y la Dra. Ruth Corcuera, especialista en arte textil (directora de Antropología del CIAFIC/Conicet)

6 García Canclini, N. (1996). Culturas híbridas, México: Grijalbo. Véase en particular el capítulo "El porvenir del pasado", donde analiza las distintas tendencias ante la exhibición del patrimonio histórico.

7 En este punto cabe aclarar que el montaje responde a una visión contemporánea de esas obras de las que no podemos reconstruir completamente su contexto original. En este sentido, toda instalación museológica no es sino una abstracción que solo toma en cuenta algunos de los significados de las obras.

8 Pérez Gollán, J. A. (2000). "Los suplicantes: una cartografía social" en Temas de la Academia: arte prehispánico. Creación, desarrollo y persistencia. Año 2, nº 2. , Buenos Aires, pp. 21- 48.

9 Hombres, animales o seres antropozoomorfos, los suplicantes fueron así denominados por sus característicos brazos en alto que rodean la cabeza como en gesto de súplica o desesperación.

10 Véase Pérez Gollán, J. A. (2000). Arte precolombino argentino, Colección de la cancillería Argentina, Buenos Aires: ediciones Banco Velox, p. 28.

11 Sobre este tema véase, Duncan, C. (1995). Civilizing rituals, inside public art museums, London-New York: Routledge.

12 Castilla, Américo con la colaboración de María José Herrera, Florencia Galesio y Rocío Boffo, Una política para los museos de la Argentina (2003), documento de la Dirección Nacional de Patrimonio y Museos, Buenos Aires.

13 García Canclini, N. op.cit. 